\title{
Addressing the Biggest (Baddest) and Best Ideas Ever: Through the Lens of Humility
}

\author{
Dr. Matthew J. Sowcik \\ Assistant Professor of Leadership Education \\ University of Florida \\ Dr. Anthony C. Andenoro \\ Assistant Professor of Leadership Education \\ University of Florida \\ Austin Council \\ Ph.D. Student \\ University of Florida
}

\begin{abstract}
Now and into the foreseeable future, both effective leadership and creativity are going to be important when addressing complex problems. The connection between effective leadership and creativity will be critical as leaders look to turn big ideas into innovative solutions. However, it seems that there is often a disconnect between the two constructs of creativity and effective leadership. The article draws upon scholarly research within the field to address this gap and better understand the power of humility to mitigate this disconnect. The goal of this article is to encourage the field of Leadership Education to look inward into how we as a community are creating an environment where creative leaders can be developed.
\end{abstract}

\section{Introduction}

In 2010, IBM conducted interviews of 1,500 corporate heads and public sector leaders across 60 nations and 33 industries looking to identify what were perceived as the most important qualities needed for effective leadership for the future (Tomasco, 2010). Number one on the list was creativity. The leaders in the study felt strongly that creativity, and the opportunity to be creative as an organization, were among the most important attributes for capitalizing on increased complexity in the $21^{\text {st }}$ century. According to this 2010 IBM study, "Creative leaders invite disruptive innovation, encourage others to drop outdated approaches and take balanced risk. They're open-minded and inventive in expanding their management and communication styles, particularly to engage with a new generation of employees, partners and customers" (Lombardo \& Roddy, 2010, p.1).

Interestingly, in the same study, 700 Chief Human Resource Officers were interviewed and $69 \%$ suggested their organization was not effective in developing creative leaders (Lombardo \& Roddy, 2010, p. 1). Additionally, 78\% of the Chief Human Resource Officers stated that their organizations were not effective at fostering collaboration and knowledge 
sharing (Lombardo \& Roddy, 2010, p. 1).

This is not the only time a disconnect between effective leadership and creativity has been found in the research. In another study of 485 leaders from around the world, $62 \%$ agreed that innovation was "very important" to the success of their organization; yet only $14 \%$ of the leaders felt that those in their organization were "very effective" at innovation (Clerkin, 2015). This wasn't from lack of trying to develop creative leaders; in the study, approximately threefourths of the respondents suggested the organization had tried to improve innovation in the organization without success. As Clerkin (2015) points out, "Among organizations that struggled with innovation, respondents pointed to lack of culture that supports innovation, and lack of leadership around innovation as the two biggest setbacks" (p. 180).

This disconnect between leadership development, creativity and innovation, or "the capacity to generate ideas...that are novel and useful," exists not just at the organizational level (Chan, Fu, Schumm, Cagan, Wood, \& Kotovsky, 2011, p.1). Leadership education, both in its curricular and non-curricular forms, has historically struggled to address the need for innovative leaders. If we know that the landscape of the $21^{\text {st }}$ century is going to be complex, changing and dependent on creative and collaborative leaders, why do we have such a difficult time developing effective creative leaders for the future? This article addresses the important but often overlooked virtue of humility as it relates to addressing this gap between leadership and creativity. Finally, the article recommends some next steps for leadership education to address humility and turn big (and possibly bad) ideas into creative solutions.

\section{Why the Chasm Exists?}

The $21^{\text {st }}$ century has required unprecedented levels of creativity and innovation to address the complex problems we are facing every day. Over the next thirty years, "wicked problems" will only increase in scope and complexity (Rittel \& Webber, 1973; Satterwhite, Miller, \& Sheridan, 2015). We will be faced with grand challenges like a global population projected to exceed 9.6 billion people, making it the greatest problem of our time (Stedman \& Andenoro, 2015). Additionally, creative leaders will be instrumental in addressing grand challenges associated with water, space, agriculture, energy and climate change.

However, it seems that creativity and effective leadership do not always naturally go together and, at times, are competing forces. One example of this was Steve Jobs, Apple Founder and former C.E.O., who was a remarkably innovative individual but struggled significantly as an effective leader. In his first stint as C.E.O., it has been suggested that his lone genius did not translate well into his leadership style, which was perceived as arrogant, abrasive, and largely ineffective (Grijalva \& Harms, 2014).

So what issues underlie the disconnect often associated with being both creative and an effective leader, like in the example of Steve Jobs? First, there is some good news. Research on the topic of creativity does point to particular characteristics that are associated with creative individuals. For example, creative individuals tend to be open to experiences, less conventional, 
self-confident, driven, highly dominant, independent, and less agreeable (Feist, 1998). In the research, the most significant effect size included characteristics like openness, conscientiousness, self-acceptance, hostility, and impulsivity (Feist, 1998).

Although it is helpful to better understand the particular characteristics likely associated with creativity, one issue that surfaces is the relationship between these characteristics and effective leadership. For example, you would be hard pressed to find research that suggests effective leaders are characteristically dominant, less agreeable, hostile, independent, or impulsive. In fact, characteristics that define effective leaders can be seen as the opposite of these creative characteristics, like putting followers first, emotional healing, balanced processing, relational transparency, and maintaining disciplined attention, which are all key components of current theories of leadership including Servant Leadership, Authentic Leadership and Adaptive Leadership (Northouse, 2012).

Associated with these creative traits are behaviors, which may also clash with effective leadership. For example, those who tend to be driven and ambitious often focus on task behaviors at the expense of relationship building. Other traits like independence can also have negative implications when it comes to effective leadership. As Feist (1998) suggests, "Independence in creative people goes along with sticking to one's beliefs in the face of doubt and skepticism by others" (p. 290). Although at times adherence to beliefs can be a positive, all too often motivated reasoning impacts the perception we have concerning our own rightness. If we hold on too tightly to our beliefs, we run the risk of alienating our stakeholders (Feist, 1998).

Aligned with these behavioral issues, especially driven by independence, is society's infatuation with the lone genius. This preoccupation leads to the interpersonal issues often related to the gap between effective leadership and creativity. As a society we place these eccentric individuals on a pedestal believing they have a monopoly on creative ideas. Due to the general belief that originality is a critical element of creativity, those looking to be creative must find a way to differentiate themselves from others (Feist, 1998). When trying to be unique, it is easy to see why individuals feel the need to cut themselves off from others, in order to develop one's own unique perspective.

This is also true when it comes to society's interest in charismatic leaders, who we believe will singlehandedly, swoop in like a superhero and save the day. For both leadership and creativity, we associate positive characteristics with this superhero, who work independent of others. As Adam Grant (2013) suggests, "Americans see independence as a symbol of strength, viewing interdependence as a sign of weakness" (p.73). Like the lone genius, the charismatic leader may distance themselves from interpersonal relationship to "promote highly self-serving and grandiose aims" (Mayo, 2017). With this fascination society has for both the lone genius and the charismatic leader, we may be inadvertently de-emphasizing the important role relationships play in both creativity and effective leadership.

If a leader is able to check their ego, in both the creative and leadership process, working with others may still present some unique problems. Most individuals are familiar with the 
benefits of diversity in the groups, especially as it relates to creativity (Bassett Jones, 2005). Research suggests that when diversity is managed successfully, it can have a positive impact on creativity, resulting in greater levels of job satisfaction, increased commitment, and a better connection with the marketplace (Bassett Jones, 2005). However, diversity and different perceptions may increase the level of conflict faced by both the leader and the team. As Margaret Heffernan points out in her TEDx talk, Dare to Disagree, leaders are particularly poor at handling conflict and often choose to avoid it (Heffernan, 2012). Furthermore, we like to work with those who are similar to ourselves, so it would take an active decision by the leader to purposefully increase diversity in our interpersonal relationships at work (Bassett Jones, 2005).

The issues associated with creativity and leadership are only amplified once an individual moves into a more advanced leadership role. As Robinson and Schroeder (2014) suggest in their book, The Idea-Driven Organization, leaders who are selected to move up in the organization are exposed to a number of factors, which make these individuals less likely to be innovative. Robinson and Schroeder (2014) suggest that as individuals get promoted into leadership positions, they gain power and this power has some debilitating effects on the idea-generating process including:

- Power reduces the complexity of a person's thinking and ability to consider alternatives.

- People with power listen less carefully and have difficulty taking into account what others already know.

- People with power are less accurate in their estimates of the interests and positions of others, and they are less open to others perspectives (p. 45).

The rhetoric often associated with leaders claiming that innovation is critically important is not backed with action at the same level. Possibly due to short-term pressures from stakeholders, ineffective management of priorities, and/or the lack of insight and attributes it takes to lead innovation, leaders delegate the idea of innovation down to others for implementation. Additionally, to address these short term pressures, leaders may outright reject novelty because they are in an evaluative mindset and look to protect themselves against failure (Grant, 2013). These perceived pressures are seen as competing demands to the promotion of creativity in leadership at all levels throughout the organization. This can be detrimental to creativity and innovation within an organization because as Scott Anthony points out, "Innovation is enough of an unnatural act in most companies that it requires the day-by-day attention of the company's top leadership team or it simply won't stick" (Anthony, 2013).

Finally, as leaders gain increased expertise and experience in a particular environment, usually associated with moving up the organization, research suggests that they become more entrenched into their particular view of the world. Grant \& Sandberg, (2016) suggest in their book, Originals: How non-conformists move the world, "As we gain knowledge about a domain, we become prisoners of our prototypes" (p. 41). Moreover, creative success in one environment does not transition easily into a different context. Although leaders tend to believe results are easily replicated in different contexts, the more successful they were in the original environment, the worse they perform in a new environment. This is due to over confidence, oversimplification 
of systems, and devaluing the importance of critical feedback needed to be successful in this new context (Grant \& Sandberg, 2016. p. 54).

\section{How do we address this Leadership and Creativity Chasm?}

As suggested above, Steve Jobs was an extraordinarily creative individual whose leadership suffered because of his narcissism and abrasive style. However, during his second appointment as Apple's C.E.O., he was able to temper his narcissistic management style and advance his leadership style (Owens, Wallace \& Waldman, 2015). By the time he resigned from Apple in 2011, the company had become the largest corporation in the United States (Dodds, 2016). Jobs had taken Apple from a market capitalization of $\$ 3$ billion in 1997, at the beginning of his second term as C.E.O., to $\$ 355$ billion at the point of his retirement (Dodds, 2016).

What changed in Steve Jobs' leadership style from his first to second stint as leader of Apple? During his second appointment at Apple, Jobs learned humility, which provided him the opportunity to be more open to others' ideas, more willing to acknowledge past failures, and more appreciative of those around him for their contributions to the organization. Jobs himself referred to his earlier experience with Apple as "awful tasting medicine . . . [that] the patient needed" (Owens, Wallace, \& Waldman, 2015, p.1203). As Owens, Wallace and Waldman (2015) point out, "Although Jobs was still seen as narcissistic, his narcissism appeared to be counterbalanced or tempered with a measure of humility, and it was this tempered narcissist who led Apple to be the most valuable company in the world during his second attempt as company president" (p. 1204).

Claremont Graduate University Professor and author Mihaly Czikszentmihalyi, after devoting 30 years of research to how creative people live and work, suggested creative individuals were "remarkable for their ability to adapt to almost any situation and to make do with whatever is at hand to reach their goals" (Czikszentmihalyi, 1996). He went on to suggest that humility is a critical part of the creative process. Czikszentmihalyi (1996) said:

Creative people are humble and proud at the same time. It is remarkable to meet a famous person who you expect to be arrogant or supercilious, only to encounter self-deprecation and shyness instead. Yet there are good reasons why this should be so. These individuals are well aware that they stand, in Newton's words, "on the shoulders of giants." Their respect for the area in which they work makes them aware of the long line of previous contributions to it, putting their own in perspective. They're also aware of the role that luck played in their own achievements. And they're usually so focused on future projects and current challenges that past accomplishments, no matter how outstanding, are no longer very interesting to them.

Humility, which according to Czikszentmihalyi is critically important to creative success, is equally as important in the leadership process. Collins (2001), in his book Good to Great, found that leaders in the most enduring successful companies demonstrated a blend of determination and personal humility. These "Level 5" leaders, as he called them, were better able 
to entertain different perspectives, manage others emotions, and connect back to the organizational goals than those who had low levels of humility (Collins, 2001). It is within this shared association with the virtue humility that we can begin to bridge the chasm between effective leadership and creativity. However, before we address bridging the gap, it is important to provide both a history and definition of humility to guide our discussion.

\section{What is Humility?}

Virtue ethicists, theologians, psychologists, scholars and practitioners have long disputed the definition of humility. Although there is no one conclusive definition, it is appropriate to explore a diverse array of viewpoints in order to grasp the underlying themes of the concept. From a purely definitional standpoint, in the Oxford Dictionary of English, humility is defined as "The quality of having a modest or low view of one's importance" (Stevenson, 2010).

Concurrently, the Merriam-Webster online dictionary describes humility as "Freedom from pride or arrogance: the quality or state of being humble" (Webster, 2006).

Humility is also integral in many religious traditions including Christianity, Buddhism and Islam and has been written and spoken about from the likes of Jesus Christ, Buddha, and several prolific Christian saints. In the New Testament of the Holy Bible, Ephesians 4:2 describes, "Be completely humble and gentle; be patient, bearing with one another in love" (The New King James Version). Sixth-century Christian monk St. Benedict of Nursia - noted as the father of Western Cenobiti Monasticism - wrote a decree in which he proposed a twelve-step method and explanation of how humility is developed in leaders and followers alike (Bekker, 2008).

Buddhism, a faith surrounded upon the central idea of self-reflection, also has connections to humility. Cooper and James (2005) note, "The true connection between the religion and environmental thought is to be found in Buddhist accounts of the virtues, those traits, such as compassion, equanimity and humility, that characterize the life of a spiritually enlightened individual" (p. 1). Humility is also a foundational piece to practicing Islam. In his discussion about humility, Tariq Ramadan (2004) in Western Muslims and the Future of Islam writes that within the Islamic tradition there are different states of human life, those of innocence and responsibility. According to Ramadan (2004), "By marrying the two states of innocence and responsibility, humility is the state that allows the human being to enter into its humanity. Humility is the source of ethics" (p. 18).

From a more contemporary, literary lens, in Mere Christianity, novelist C.S. Lewis (2001) expresses humility as "not thinking less of yourself, but thinking of yourself less" (p. 122). In the scholastic realm, Tangney (2000), in her scholarly review and critique of the existing theoretical literature, identifies a number of humility's key elements that include:

- An accurate portrayal of one's abilities and accomplishments

- The ability to recognize one's strengths and limitations

- Having an openness to new ideas, conflicting information and wisdom 
- Recognizing one's capabilities and achievements — one's place in the world — with perspective (p.73).

With these claims, it is important to make the distinction between modesty and humility. Tangney (2000) notes "the theological, philosophical, and psychological literatures portray humility as a rich, multifaceted construct, in sharp contrast to some definitions that emphasize low self-esteem or low self-worth" (p. 73). Peterson and Seligman (2004) similarly comment on this notion, explaining "the term modesty refers primarily to the moderate estimation of one's merits or achievements and also extends into other issues relating to propriety in dress and social behavior" (p. 463). In essence, humble people will not deliberately misjudge information in order to protect, fix, or affirm their own persona (Peterson \& Seligman, 2004). For humble individuals, there should be no tread toward arrogance, and no fervent craving to view or present themselves as being better than they actually are (Peterson \& Seligman, 2004). As C. S. Lewis suggests, "Perfect humility dispenses with modesty" (1941, p. 270).

As we attempt to define humility for the purpose of this article, one universal theme throughout the literature is the notion that humility involves an inclination to have a "nondefensive willingness to see the self accurately" (Peterson \& Seligman, 2004, p. 463). This proper viewpoint allows individuals to see experiences in their lives as neither better nor worse than they are, and instead with a great deal of precision and transparency. An additional reflection, when defining humility, is the different frameworks in which this accurate perspective takes place. A very common element of humility is an accurate view of oneself (intrapersonal perspective). This includes the ability to accurately assess one's strengths and limitations without exaggeration.

The next shared perspective, and the one most often associated with humility, is the relational nature of humility (Tangney, 2000). This interpersonal element of humility serves as an accurate understanding of one's relationship with others and the importance of that relationship in one's life. This can include the important role others play in providing feedback, different perspectives, and complementary strengths. The final relational element involves a proper view of one's relationship with the larger environment and the impact this awareness has on self-awareness. Humility research points to this idea of being "unselved" and gaining an appreciation that each of us are part of a much larger environment or system (Tangney, 2000). Buddha may have stated this better than anyone, "Act always as if the future of the universe depends on what you do, while laughing at yourself for thinking that whatever you do makes any difference" (Nepo, 2007, p.243). Drawing on these connections we define humility as a proper perspective of oneself, one's relationship with others and one's connection to the larger environment.

\section{How Does Humility Help Mitigate the Challenges Associated with Leadership and Creativity?}

John Ruskin, English critic, essayist, \& reformer, suggested, "I believe that the first test of a truly great man is his humility. I don't mean by humility, doubt of his power. But really great 
men have a curious feeling that the greatness is not of them, but through them" (Lloyd \& Mitchinson, 2009, p. 150). One would assume, especially based on statements like this, that humility would be a universally accepted and studied construct, however, it has received very little interest in the social science research. Yet, over the last two decades the construct has gained more attention in both Positive Organizational Psychology and the study of leadership. Over this time, those conducting research on humility have realized the benefits of this characteristic including its impact on prosocial behaviors such as generosity (Exline \& Hill, 2012; LaBouff, Rowatt, Johnson, Tsang, \& Willerton, 2012), self-esteem (Exline \& Geyer, 2004), better performance on the job (Exline, 2012) and forgiveness (Powers Nam, Rowatt, \& Hill, 2007).

Humility Impacts the Intrapersonal Issues. When addressing the challenges associated with effective leadership and creativity, it is important to focus on the impact humility ha $\mathrm{s}$ on the intrapersonal level. Addressing this intrapersonal level provides an accurate perspective of oneself as it relates to our role in being both creative and effective as a leader. Of all areas where humility has been explored, intellectual humility has received the most attention in the research. Out of this research has come a better understanding of the important role humility plays in academic achievement, being open to different perspectives, and even scientific discovery (Rowatt, Ottenbreit, Nesselroade \& Cunningham, 2002). This can be directly attributed to humility's impact on one's openness to new paradigms and different perspectives (Vera \& Rodriguez-Lopez, 2004).

Another intrapersonal issue that emerges when addressing creative leadership is the strong relationship between creative success and traits like hostility, arrogance, being highly dominate, and being less agreeable. Once again, Steve Jobs' narcissistic behavior was the perfect example of a creative individual who struggled with a difficult (and ineffective) leader style. However, in a study completed by Owens, Walker and Waldman (2015) the researchers found that humility was the moderator which made narcissistic leaders excel in terms of leader effectiveness and follower outcomes. The researchers suggested, "Narcissistic leaders may not be doomed to fail and may not necessarily need to abandon their strong agentic tendencies if they can instead allow these tendencies to be tempered by counterbalancing characteristics" (Owens, Walker, \& Waldman, 2015, p. 1205). The counterbalancing characteristic the authors were referring to was humility.

Humility Impacts the Interpersonal Issues. One common misperception of creativity is that the lone genius, who disassociates from the "average" individual to create space for divine inspiration to occur, is more creative. However, research supports a very different model of creativity and innovation. Inclusivity and inclusive leadership have been shown to increase psychological safety, which in turn, enhanced employee involvement in creative work (Carmeli, Reiter-Palmon, \& Ziv, 2010). Additionally, research conducted by Catalyst Research Centers (2016) who surveyed more than 1,500 workers from Australia, China, Germany, India, Mexico, and the U.S., also found that inclusion was linked to self-reported innovation. This research also found that humility is one of four critical leadership factors, along with empowerment, courage and accountability, which create an environment where employees feel included. Furthermore, 
the research found that employees who perceive humility and the three other altruism behaviors from their manager, reported being more innovative, including an increase in new work ideas and positive changes to their work environment (Catalyst, 2016).

Another area where interpersonal relationships are important in creativity is receiving honest feedback and coaching from others. One of the more consistent findings in socialpsychological research is that people tend to be overconfident on the way they perceive their own abilities, especially when the abilities are subjective like creativity and leadership (Dunning, Meyerowitz, and Holzberg, 1989; Moore \& Healy, 2008). Instead of attempting to assess our own originality, we are more creative when we receive feedback from others (Grant, 2016). It has been suggested that individuals high in humility have an eagerness to learn from others, have higher levels of cooperation, and are more likely to ask for advice (Vera \& Rodriguez-Lopez, 2004; Exline, 2012). If this is the case, leaders with increased levels of humility will have the appropriate mindset to challenge overconfidence and confirmation bias, leading to creative ideas that are more likely to be useful and successful.

Finally, as mentioned above, the value of diversity should result in different perspectives promoting creativity and problem-solving capabilities (Shalley \& Gilson, 2004). However, all too often conflict is also an outcome of these diverse perspectives. If a leader does not handle the conflict effectively, there is a chance the environment will eliminate any benefits of the diverse perspectives. If a leader is able to channel conflict successfully, the conflict can increase the likelihood for creativity and innovation in the future (Bassett Jones, 2005). Leaders with humility have a genuine desire to serve, respect and help others, which is recognized by colleagues. Research conducted by Adam Grant, in his book Give and take: Why helping others drives our success, "found when takers presented suggestions for improvement, colleagues were skeptical of their intentions, writing them off as self-serving. But when ideas that might be threatening were proposed by givers, their colleagues listened and rewarded them for speaking up, knowing they were motivated by genuine desire to contribute" (2013, p. 76).

Humility Impacts the Systemic Issues. This quote by Peter Senge helps to put into perspective the important role systems play when addressing creative ideas: "Business and human endeavors are systems...we tend to focus on snapshots of isolated parts of the system. And wonder why our deepest problems never get solved" (Senge, 1990, p. 7). If humility is to address the issues associated with moving these creative ideas forward, then it would have to address the issues embedded in systems thinking and more specifically, complex adaptive systems. The most effective way to explore humility's role in this context is to understand how it relates to adaptive leadership, which is grounded in a systems perspective.

One of the first concerns when trying to address the issues of creativity and leadership, at the larger systems perspective, is our oversimplification of the system. Leaders tend to be overconfident in the role they play when it comes to creativity and change. Additionally, leaders can oversimplify the process believing that past success in a particular context can be easily applied to other situations with the same level of success. As Heifetz, Grashow, \& Linsky (2009) point out: 
The most common leadership failure stems from trying to apply technical solutions to adaptive challenges. Authorities make this mistake because they misinterpret or simplify the problem, fail to see how the organizational landscape has changed, or prefer a "solution" that will avoid disruption or distress in the organization (p. 71).

This will often leave the leader surprised when a creative idea does not translate successfully into a different environment. Vera \& Rodriguez-Lopez (2004, p.399) suggest that:

Humble leaders have a more realistic perspective of the complexity of the world, and acknowledge the limitations of their current paradigms and strategies. They are not anchored to old solutions, no matter how successful these solutions have been in the past (p. 399).

Humility allows leaders to continually "get on the balcony," as Heifetz, Grashow, \& Linsky, (2009) suggest and appreciate the bigger picture. From this humble mindset of a systems perspective, leaders are better able to identify whether the challenges are technical or adaptive in nature and how to creatively address those issues.

The next concern when addressing systemic issues of creativity and leadership is the larger issue of proposing change. When addressing technical challenges, or problems that are clearly defined and have a known solution that can be easily implemented, then the directive from the leader can be handed down with some success (Heifetz, Grashow, \& Linsky, 2009). These technical challenges are not the issues we are addressing in this article. Yet, even in these situations increased humility may be important since research on self-aggrandizing leaders suggests they "tend to make riskier investments, pay higher premiums for acquisitions, pursue more dynamic and grandiose strategies, and create fluctuating organizational performance" $(\mathrm{Ou}$, Tsui, Kinicki, Waldman, Xiao \& Song, 2014, p. 4). When attending to adaptive issues, and drawing on creativity to address these issues, it is important to give the work back to the people (Northouse, 2012). Although leaders need to provide direction, structure and space for others to feel secure, they run the risk of inhibiting creativity and change by being overly involved. Leaders who lack humility may have difficulty directing attention away from themselves and turning the work back to the people.

Even though the leader is responsible for turning the work back over to the people, it is critical that the leader establishes a culture where creativity can flourish. Creativity is not a directive handed down without support from leadership at the top levels. Instead, as Kotter and Heskett (1992) suggested, "Only through leadership can one truly develop and nurture culture that is adaptive to change" (p. 3). Leaders who lack humility set a vision for creativity and change that addresses their own self-interests; this may include protecting their ego and job by establishing cultures which shift the fault away from them when the outcomes are not realized. Leaders with humility believe in a collective organizational vision that focuses on all the stakeholders within the systems and work with others to create accountability within that culture (House and Aditya, 1997). 


\section{Next Steps}

This article only begins to scratch the surface of the impact that humility can have on the tension that exists between effective leadership and creativity. If Leadership Education is to develop individuals who will be able to turn big! (bad?) ideas into creative solutions, then it is going to be necessary for the field of Leadership Education to practice what it preaches. The field will need to start addressing humility development in leadership education programs. Even though humility has a significant impact on all the facets of effective leadership, including creativity, there are very few programs across the country which include humility in their curriculum. This is surprising due to the important role humility plays in some of the major theories of leadership. For example, humility is an explicit component of Servant Leadership showing up as a key characteristic in different Servant Leadership Models like Dennis and Bocarnea (2005), Wong and Davey (2007) and van Dierendonck and Nuijten (2011) (Van Dierendonck, 2011). Additionally, as Morris, Brotheridge, and Urbanski (2005) point out, "In addition to its parallels with servant leadership, humility is consistent with an emerging emphasis on authentic leadership" (p. 1339). A leader's ability to self-examine, accept personal shortcomings and resist the need to be the center of attention, are all key elements of Authentic Leadership and humility.

It has also been argued that humility is a key component of leadership theories like Transformational Leadership, Shared Leadership and Adaptive Leadership (Chiu, Owens, \& Tesluk, 2016; Morris, Brotheridge, and Urbanski, 2005; Obolensky, 2014). However, while humility is an explicit component of theories like Authentic Leadership or Servant Leadership and implied in theories like Adaptive leadership, Servant Leadership and Transformational leadership, it is often passed over in leadership education programs. The absence of humility in leadership education may be directly tied to the lack of research, content knowledge and/or resources necessary to teach humility in this setting.

The curriculum is not the only issue in higher education and organizations when trying to develop leaders with humility. Inherently, the programs themselves promote narcissistic behaviors. In many cases, exclusive leadership development programs, both in higher education and in corporate America, recruit only the "best" students/employees to participate in the leadership program. During the recruitment process it is repeatedly emphasized how the program/school only selects the very "best". Then, once the program begins, both the faculty/facilitators and students continually reinforce the belief that this is a "special" group of individuals going through a "very important" program. This constant reinforcement of in-group importance cannot help but promote egotism throughout the group. It is critical for the field to start exploring how the administration of our leadership programs, both in higher education and corporate America, are impacting the development of leaders.

Although the future is unknown, it is almost certain that both leadership effectiveness and creativity will play an important role in our future success. It is critically important that we continue to research the positive benefits that humility has on areas like leader development, leadership development and creativity. This research will likely provide insight into how we can 
offer leadership development opportunities that increase student's humility. By providing humility developing experiences in leadership programs, it is possible that we can begin to develop leaders who are able to turn big ideas into creative solutions that will transform our world.

\section{References}

Anthony, S. (2013). Your innovation problem is really a leadership problem. Harvard Business Review. Retrieved on April 5 from https://hbr.org/2013/02/your-innovation-problem-isreally-a-leadership.

Bassett Jones, N. (2005). The paradox of diversity management, creativity and innovation. Creativity and innovation management, 14(2), 169-175.

Bekker, C. J. (2008). Leading with the Head bowed down: Lessons in Leadership Humility from the Rule of St. Benedict of Nursia. Inner Resources for Leaders, 1(3), 1-10.

Carmeli, A., Reiter-Palmon, R., \& Ziv, E. (2010). Inclusive leadership and employee involvement in creative tasks in the workplace: The mediating role of psychological safety. Creativity Research Journal, 22(3), 250-260.

Catalyst. (2016, May 13). Inclusive Leadership: The View From Six Countries. Retrieved April 5, 2017, from http://www.catalyst.org/knowledge/inclusive-leadership-view-six-countries

Chan, J., Fu, K., Schunn, C., Cagan, J., Wood, K., Kotovsky, K. (2011). On the benefits and pitfalls of analogies for innovative design: Ideation performance based on analogical distance, commonness, and modality. Journal of Mechanical Design, 133 (8), 081004.

Chiu, C.-Y., Owens, B. P., \& Tesluk, P. E. (2016, September 12). Initiating and Utilizing Shared Leadership in Teams: The Role of Leader Humility, Team Proactive Personality, and Team Performance Capability. Journal of Applied Psychology. Advance online publication. http:// dx.doi.org/10.1037/ap10000159

Clerkin, C. (2015). Creative leadership and social intelligence: The keys to leading in the digital age. In Matthew Sowcik et al. (Eds.). Leadership 2050: Critical challenges, key contexts, and emerging trends. Emerald Publishing.

Collins, J. C. (2001). Good to great: Why some companies make the leap... and others don't. Random House.

Cooper, D. E., \& James, S. P. (2005). Buddhism, virtue and environment. Ashgate. 
Csikszentmihalyi, M. (1996, July 01). The creative personality. Psychology Today. Retrieved April 5, 2017, from https://www.psychologytoday.com/articles/199607/the-creativepersonality

Dennis, R. S., \& Bocarnea, M. 2005. Development of the servant leadership assessment instrument. Leadership and Organization Development Journal, 26, 600-615.

Dodds, C. (2016, February). Steve Jobs: Success Story. Investopedia. Retrieved April 15, 2017 from http://www.investopedia.com/university/steve-jobs-biography/steve-jobs-successstory.asp.

Dunning, D., Meyerowitz, J. A., \& Holzberg, A. D. (1989). Ambiguity and self-evaluation: The role of idiosyncratic trait definitions in self-serving assessments of ability. Journal of Personality and Social Psychology, 57(6), 1082-1090.

Exline, J. J. (2012). Humility and the Ability to Receive from Others. Journal of Psychology \& Christianity, 31(1).

Exline, J. J., \& Geyer, A. L. (2004). Perceptions of humility: A preliminary study. Self and Identity, 3(2), 95-114.

Exline, J. J., \& Hill, P. C. (2012). Humility: A consistent and robust predictor of generosity. The Journal of Positive Psychology, 7(3), 208-218.

Feist, G. J. (1998). A meta-analysis of personality in scientific and artistic creativity. Personality and Social Psychology Review, 2(4), 290-309.

Grijalva, E., \& Harms, P. D. (2014). Narcissism: An integrative synthesis and dominance complementarity model. The Academy of Management Perspectives, 28(2), 108-127.

Grant, A. (2013). Give and take: Why helping others drives our success. Penguin.

Grant, A., \& Sandberg, S. (2016). Originals: How non-conformists move the world. Viking Adult.

Heffernan, M. (2012). Transcript of "Dare to disagree". Retrieved April 20, 2017, from https://www.ted.com/talks/margaret_heffernan_dare_to_disagree/transcript?language=en

Heifetz, R. A., Grashow, A., \& Linsky, M. (2009). The practice of adaptive leadership: Tools and tactics for changing your organization and the world. Harvard Business Press.

House, R. J., \& Aditya, R. N. (1997). The social scientific study of leadership: Quo vadis? Journal of management, 23(3), 409-473. 
Kotter, J.P. and Heskett, J.L. (1992) Corporate Culture and Performance. The Free Press, New York.

LaBouff, J. P., Rowatt, W. C., Johnson, M. K., Tsang, J. A., \& Willerton, G. M. (2012). Humble persons are more helpful than less humble persons: Evidence from three studies. The Journal of Positive Psychology, 7(1), 16-29.

Lewis, C. S. (2001). Mere Christianity. Zondervan.

Lewis, C. S. (1941). The Weight of Glory 1. Theology, 43(257), 263-274.

Lloyd, J., \& Mitchinson, J. (2009). If Ignorance Is Bliss, Why Aren't There More Happy People? Smart Quotes for Dumb Times. Crown.

Lombardo, B. J., \& Roddy, D. J. (2010). Cultivating organizational creativity in an age of complexity. IBM Institute of Business Value. Retrieved April 10, 2017 from http://docplayer.net/33031210-Cultivating-organizational-creativity-in-an-age-ofcomplexity.html.

Mayo, M. (2017, April 07). If Humble People Make the Best Leaders, Why Do We Fall for Charismatic Narcissists? Harvard Business Review. Retrieved April 15, 2017, from https://hbr.org/2017/04/if-humble-people-make-the-best-leaders-why-do-we-fall-forcharismatic-narcissists

Moore, D. A., \& Healy, P. J. (2008). The trouble with overconfidence. Psychological review, 115(2), 502.

Morris, J. A., Brotheridge, C. M., \& Urbanski, J. C. (2005). Bringing humility to leadership: Antecedents and consequences of leader humility. Human relations, 58(10), 1323-1350.

Myers, D. G. (1995). Humility: Theology meets psychology. Reformed Review, 48, 195-206.

Nepo, M. (2007). The exquisite risk: daring to live an authentic life. Harmony.

Northouse, P. G. (2012). Leadership: Theory and practice. Sage.

Obolensky, M. N. (2014). Complex adaptive leadership: Embracing paradox and uncertainty. Gower Publishing, Ltd..

Ou, A. Y., Tsui, A. S., Kinicki, A. J., Waldman, D. A., Xiao, Z., \& Song, L. J. (2014). Humble chief executive officers' connections to top management team integration and middle managers' responses. Administrative Science Quarterly, 59(1), 34-72. 
Owens, B. P., Wallace, A. S., \& Waldman, D. A. (2015). Leader narcissism and follower outcomes: The counterbalancing effect of leader humility. Journal of Applied Psychology, 100(4), 1203.

Peterson, C., \& Seligman, M. E. (2004). Character strengths and virtues: A handbook and classification (Vol. 1). New York, NY: Oxford University Press.

Powers, C., Nam, R. K., Rowatt, W. C., \& Hill, P. C. (2007). Associations between humility, spiritual transcendence, and forgiveness. Research in the social scientific study of religion, 18,75 .

Ramadan, T. (2004). Western Muslims and the future of Islam. New York, NY: Oxford University Press.

Rittel, H. \& Webber, M. (1973). Dilemmas in a general theory of planning. Policy Sciences, 4 , 155-169.

Robinson, A. G., \& Schroeder, D. M. (2014). The Idea-driven Organization: Unlocking the Power in Bottom-up Ideas. Berrett-Koehler Publishers.

Rowatt, W. C., Ottenbreit, A., Nesselroade Jr, K. P., \& Cunningham, P. A. (2002). On Being Holier Than Thou or Humbler Than Thee: A Social Psychological Perspective on Religiousness and Humility. Journal for the Scientific Study of Religion, 41(2), 227-237.

Satterwhite, R., Miller, W.M., \& Sheridan, K. (2015) Leadership for sustainability and peace: Responding to the wicked challenges of the future. In Matthew Sowcik et al. (Eds.). Leadership 2050: Critical challenges, key contexts, and emerging trends. Emerald Publishing.

Senge, P. (1990). The fifth discipline. The Art \& Practice of Learning Organization. Doubleday, New York.

Shalley, C. E., \& Gilson, L. L. (2004). What leaders need to know: A review of social and contextual factors that can foster or hinder creativity. The Leadership Quarterly, 15(1), 33-53.

Stedman, N.L.P. \& Andenoro, A.C. (2015) Emotionally engaged leadership: Shifting paradigms and creating adaptive solutions for 2050. In Matthew Sowcik et al. (Eds.). Leadership 2050: Critical challenges, key contexts, and emerging trends. Emerald Publishing.

Stevenson, A. (Ed.). (2010). Oxford dictionary of English. Oxford University Press, USA.

Tangney, J. P. (2000). Humility: Theoretical perspectives, empirical findings and directions for future research. Journal of Social and Clinical Psychology, 19(1), 70-82. 
Tomasco, S. (2010, May 18). IBM 2010 Global CEO Study: Creativity Selected as Most Crucial Factor for Future Success. Retrieved March 19, 2016, from IBM: http://www03.ibm.com/press/us/en/pressrelease/31670.wss

Van Dierendonck, D. (2011). Servant leadership: A review and synthesis. Journal of management, 37(4), 1228-1261.

Van Dierendonck, D., \& Nuijten, I. (2011). The Servant-Leadership Survey (SLS): Development and validation of a multidimensional measure. Journal of Business and Psychology, 26, 249-267.

Vera, D., \& Rodriguez-Lopez, A. (2004). Strategic Virtues: Humility as a Source of Competitive Advantage. Organizational Dynamics, 33(4), 393-408.

Webster, M. (2006). Merriam-Webster online dictionary. Retrieved April 5, 2017, from https://www.merriam-webster.com/dictionary/humility

Wong, P. T. P., \& Davey, D. 2007. Best practices in servant leadership. Paper presented at the Servant Leadership Research Roundtable, Regent University, Virginia Beach, VA

\section{Author Biographies}

Matthew J. Sowcik, Ph.D., is an Assistant Professor of Leadership Education in the Department of Agricultural Education and Communication at the University of Florida. Dr. Sowcik teaches courses in Leadership Development, Fostering Innovation Through Leadership, Groups and Teams, Organizational Leadership, Developing Tools for a Changing World, and numerous other courses on the undergraduate and graduate level. His research specialization is in humility and the creation of Organizational Leadership programs.

Anthony C. Andenoro, Ph.D., is an Assistant Professor of Leadership Education and the Director of the Challenge 2050 Project at the University of Florida. His research builds human capacity in learners and stakeholders to address complex problems. He has procured nearly $\$ 10$ million in grant funding and served as the project lead for the National Leadership Education Research Agenda. andenoro@ufl.edu

Austin Council is a doctoral student at the University of Florida in the Department of Agricultural Education and Communication. His research interests are primarily in leadership education focusing on the virtue of humility. Before pursuing his $\mathrm{PhD}$, Austin served as a middle school social studies teacher in Alachua, Florida. acouncil15@ufl.edu 